Article

\title{
Investigation on an Injection Strategy Optimization for Diesel Engines Using a One-Dimensional Spray Model
}

\author{
Intarat Naruemon ${ }^{\mathbb{D}}$, Long Liu * ${ }^{\mathbb{D}}$, Qihao Mei and Xiuzhen Ma \\ College of Power and Energy Engineering, Harbin Engineering University, Harbin 150001, China; \\ kniisnd@gmail.com (I.N.); mqh1447251725@hrbeu.edu.cn (Q.M.); maxiuzhen@hrbeu.edu.cn (X.M.) \\ * Correspondence: liulong@hrbeu.edu.cn; Tel.: +86-451-8251-8036
}

Received: 18 October 2019; Accepted: 30 October 2019; Published: 5 November 2019

\begin{abstract}
Common rail systems have been widely used in diesel engines due to the stricter emission regulations. The advances in injector technology and ultrahigh injection pressure greatly promote the development of multiple-injection strategy, leading to the shorter injection duration and more variable injection rate shape, which makes the mixing process more significant for the formation of pollutant emission. In order to study the mixing process of diesel sprays under variable injection rate shapes and find the optimized injection strategy, a one-dimensional spray model was modified in this paper. The model was validated by the measured spray penetrations based on shadowgraphy experiments with the varying injection rate. The simulations were performed with five injection rate shapes, triangle, ramping-up, ramping-down, rectangle and trapezoid. Their spray penetrations, entrainment rates and equivalence ratios along spray axial distance are compared. The potentials of multiple-injection and gas-jet after end-of-injection (EOI) to improve mixing process and emission reduction are discussed finally. The results indicated that ramping-up injection rate obtains the highest entrainment rate after EOI, and it needs 1.5 times of injection duration for the entrainment wave to arrive at the spray tip. For the other four injection rates, the sprays can be treated as a steady-like state, needing twice of injection duration from EOI to the time the entrainment wave reaches the spray tip. The multiple-injection with proper injection rate shape enhanced the entrainment rate, and the gas-jet after EOI affected the mixture distribution and entrainment rate in spray tail under ramping-down injection rate.
\end{abstract}

Keywords: diesel engines; pollutant emission reduction; mixing process; advanced injection strategy; varying injection rate

\section{Introduction}

With the implementation of more stringent emission regulations, such as US Tier 3 and post-Euro 6, diesel engines are facing unprecedented challenges to reduce their adverse environmental impact in terms of pollutant and greenhouse emissions. To cope with the emission problem and improve the performance of diesel engines, the common rail technology has flourished around the world. The advanced fuel injection technologies in a common rail system, such as the ultrahigh injection pressure [1-4] and the multiple-injection strategy [5-7] as well as the high control accuracy [8], have greatly improved the performance of diesel engines. Under the action of ultrahigh injection pressures, the fuel can be injected into the cylinder in a short time, while the multiple-injection strategy divides the whole injection duration into many parts, creating shorter injection durations. Short injection duration often causes EOI much earlier than ignition under certain conditions, such as premixed charge combustion ignition (PCCI) and low temperature combustion (LTC) cases, resulting in the more 
complicated and crucial mixing process after EOI. Moreover, it is known that there are the ramping-up part during the initial injection period and the ramping-down part during the late injection period in a typical injection rate profile $[9,10]$. The shorter the injection duration, the higher the proportion of the ramping part. In the case of a small fuel injection quantity with a short injection duration, the injection rate shape always tends to be triangular [11,12], whose spray mixing characteristics are quite different from that of the commonly used injection rate shapes, like the square, boot or rectangle $[9,10,13]$. Besides, the advanced innovation of piezoelectric injectors makes a significant contribution to the extremely fast needle response time [14,15], meaning it is easer for diesel engines to adopt highly defined injection rate shapes to improve their performance. In this way, the varying injection rate shape plays a more and more important role in the fuel injection of diesel engine, which deserves in-depth study.

Several achievements over the last decade have shown the great influence that the injection rate shape has on the pollutant emissions and performance of diesel engines. Based on the experimental method, Macian et al. [14] found that the ramp injection rate profiles was able to influence the premixed phase of combustion and reduce the radial position of the ignition. Mohan et al. [16] using the KIVA4 computational fluid dynamics (CFD) code found that injection rate-shaping could not only lower NOx emissions, but also cut down the brake-specific fuel consumption and soot emissions at the same time. Also with the aid of KIVA4-CHEMKIN code, Tay et al. [17] discovered that the start of combustion was subject to the injection rate-shaping, with the combustion phasing and combustion duration controlled simultaneously. Even for the ammonia injection rather than the diesel fuel injection, Lamas et al. [18] found that the varying injection rate shapes, including the rectangular, triangular, or parabolic, took distinct propensities to NOx reduction in a hydrogen-diesel engine by a CFD model. It can be summarized justifiably from these researches that the varying injection rate shape indeed has a potential to optimize the engine combustion and emission characteristics. However, the spray mixing characteristic, which plays a leading role in the combustion process and emission formation, has not been investigated thoroughly. Then another more comprehensive study has been accomplished by Han et al. [19] using CFD simulations. They concluded that benefiting from the longer penetration and smaller SMD, the early injection stage would undergo a more sufficient atomization and mixing process under the left triangle and rectangle injection rate shapes, while more combustible mixture and the longest ignition delay period are formed in the late injection stage of the right triangle injection rate shape. The result reveals that different triangle injection rate shapes have different advantages in the spray mixing characteristic and combustion process. Nevertheless, the research above is aimed at the free-piston engine generator (FPEG), considering the phenomenon of fuel spray impingement. In this way, the complete and detailed spray development process is not available for analysis, but it provides a certain guidance and reference for related investigations on diesel engines. In addition, there are too many complicated factors involving in the CFD simulation, such as the fuel breakup, evaporation, mixing, turbulence dissipation and combustion, which all are sensitive to the computational accuracy. In the meantime, the results of spray mixing characteristic have not been validated by experimental data. Thus, the CFD method is not suitable for the preliminary and robust analysis of spray development. Instead, some simplified spray models, like the quasi-dimensional model of Mrzljak et al. [20], the one-dimensional spray model of Cheng et al. [21], and the two-dimensional spray model of Marčiča et al. [22], have shown superiority in studying the spray characteristics. However it is a pity that those models didn't investigate the influence of various injection rate shapes on the spray characteristics, so a simplified diesel spray model with varying injection rate shape as the core, ignoring some complicated yet uninfluential factors, is still badly needed to study the mixing characteristics of diesel spraying.

Therefore, this paper employed an improved one-dimensional diesel spray model based on that proposed by Musculus et al. [23] to analyze the potential of varying injection rate shapes to lower the pollutant emissions of diesel engine and find the optimized injection strategy. Five injection rate shapes were considered: triangle, ramping-up, ramping-down, rectangle and trapezoid. For model validation, the diesel spray penetration even after EOI was compared with the shadowgraph data of 
non-combusting diesel sprays in a constant volume chamber. Then the mixing process was studied by calculating and analyzing the spray penetrations, entrainment rates and equivalence ratio distributed along the spray axial distance. After that, the improved mixing characteristics of the multiple-injection strategy that consists of ramping-down and ramping-up injection rates were discussed in depth. Finally, this paper also investigated the effect of the gas-jet after EOI on mixture distribution and emission reduction under the ramping-down injection rate shape.

\section{Model Description}

\subsection{Spray Model}

After EOI, the deceleration state of turbulent sprays has been found to travel downstream from the injector nozzle, meanwhile, the entrainment rate of the passing region is greatly enhanced. The propagation of the increased entrainment region is commonly known as the "entrainment wave".

The original one-dimensional discrete spray model, developed by Musculus et al. [23], could not only predict the entrainment wave in diesel spray, but also calculate the spray penetration. The computation results showed that the spray penetration after the entrainment wave arrived at the spray tip was smaller when compared with that of a steady jet. Moreover, under the action of the entrainment wave, the dependence of spray penetration on time transited from the square-root to the fourth-root. This result was validated by several experimental data. It indicates that this model has a significant advantage in mimicking the diesel spray propagation after EOI. However, the original model mainly focused on the constant injection rate case and didn't show any application for the varying injection rate. To overcome this limitation, the original model is improved in this paper to introduce the effect of varying injection rate on the spray propagation by calculating the velocity at the nozzle exit under varying fuel mass flow rate. Because based on the one-dimensional discrete spray model that proposed by Musculus et al. [23], the improved one has the same assumptions as the former. Furthermore, taking the coking and cavitation phenomenon as well as the liquid diesel spray contraction into account, the nozzle diameter is used with a discharge coefficient in computation. Figure 1 shows the schematic diagram of one-dimensional discrete diesel spray model. The fuel mass and axial momentum in each control volume are solved by the transport Equations (1) and (2).

$$
\begin{gathered}
\frac{\partial m_{\mathrm{f}}}{\partial t}=\dot{m}_{\mathrm{f}, \text { in }}-\dot{m}_{\mathrm{f}, \text { out }} \\
\frac{\partial M}{\partial t}=\dot{M}_{\text {in }}-\dot{M}_{\text {out }}
\end{gathered}
$$

where $m_{\mathrm{f}}$ is fuel mass and $M$ is axial momentum in a control volume. Overdot means integral flux crossing the inlet or outlet of each control volume. Where $m_{\mathrm{f}}$ is fuel mass and $M$ is axial momentum in a control volume. Using an upwind differencing scheme, the discretized equations for fuel mass and momentum are:

$$
\begin{aligned}
& m_{\mathrm{f}, \mathrm{i}}(t+\Delta t)=m_{\mathrm{f}, \mathrm{i}}(t)+\rho_{\mathrm{f}}\left[\beta_{\mathrm{i}-1} \cdot \overline{\bar{X}}_{\mathrm{f}, \mathrm{i}-1}(t) \cdot \overline{\bar{u}}_{\mathrm{i}-1}(t) \cdot A_{\mathrm{i}-1}-\beta_{\mathrm{i}} \cdot \overline{\bar{X}}_{\mathrm{f}, \mathrm{i}}(t) \cdot \overline{\bar{u}}_{\mathrm{i}}(t) \cdot A_{\mathrm{i}}\right] \cdot \Delta t \\
& M_{\mathrm{i}}(t+\Delta t)=M_{\mathrm{i}}(t)+\left\{\beta_{\mathrm{i}-1} \cdot \overline{\bar{\rho}}_{\mathrm{i}-1}(t) \cdot\left[\overline{\bar{u}}_{\mathrm{i}-1}(t)\right]^{2} \cdot A_{\mathrm{i}-1}-\beta_{\mathrm{i}} \cdot \overline{\bar{\rho}}_{\mathrm{i}}(t) \cdot\left[\overline{\bar{u}}_{\mathrm{i}}(t)\right]^{2} \cdot A_{\mathrm{i}}\right\} \cdot \Delta t
\end{aligned}
$$

where $\overline{\bar{X}}_{\mathrm{f}, \mathrm{i}}(t), \overline{\overline{\mathrm{u}}}_{\mathrm{i}}(t)$ are the fuel volume fraction and fluid velocity averaged over the spray cross section at $\mathrm{i}$ - th control volume respectively, $\rho_{\mathrm{f}}$ is the fuel density, $\beta_{\mathrm{i}}$ is the coefficient which determines the radial velocity profile at $\mathrm{i}$ - th control volume, $A_{\mathrm{i}}$ is the cross-sectional area at the downstream surface 
of $\mathrm{i}$ - th control volume, $\overline{\bar{\rho}}_{\mathrm{i}}(t)$ is the cross-section averaged fluid density at $\mathrm{i}$ - th control volume. $A_{\mathrm{i}}$, $\overline{\bar{X}}_{\mathrm{f}, \mathrm{i}}(t), \overline{\overline{\mathrm{u}}}_{\mathrm{i}}(t)$ and $\overline{\bar{\rho}}_{\mathrm{i}}(t)$ are given by the Equations (5)-(8) respectively: align these symbols

$$
\begin{gathered}
A_{\mathrm{i}}=\pi \cdot\left[\mathrm{Z}_{\mathrm{i}} \cdot \tan (\theta / 2)\right]^{2} \\
\overline{\overline{\mathrm{X}}}_{\mathrm{f}, \mathrm{i}}(t)=\frac{m_{\mathrm{f}, \mathrm{i}}(t)}{\rho_{\mathrm{f}} \cdot A_{\mathrm{i}} \cdot \Delta \mathrm{Z}} \\
\overline{\overline{\mathrm{u}}}_{\mathrm{i}}(t)=\frac{\mathrm{M}_{\mathrm{i}}(t)}{\overline{\bar{\rho}}_{\mathrm{i}}(t) \cdot A_{\mathrm{i}} \cdot \Delta \mathrm{Z}} \\
\overline{\bar{\rho}}_{\mathrm{i}}(t)=\rho_{\mathrm{f}} \cdot \overline{\bar{X}}_{\mathrm{f}, \mathrm{i}}(t)+\rho_{\mathrm{a}}(t) \cdot\left[1-\overline{\bar{X}}_{\mathrm{f}, \mathrm{i}}(t)\right]
\end{gathered}
$$

where $\Delta \mathrm{Z}$ is the length of a control volume, $\theta$ is the spreading angle of diesel spray, $\rho_{\mathrm{a}}(t)$ is the density of surrounding gas. $A_{\mathrm{i}}$ is evaluated at the axial midpoint of each control volume in the spray model of Musculus et al. [23], however, $A_{\mathrm{i}}$ defined at the downstream surface area of a control volume gives almost the same results when a sufficiently small $\Delta \mathrm{Z}$ is used.

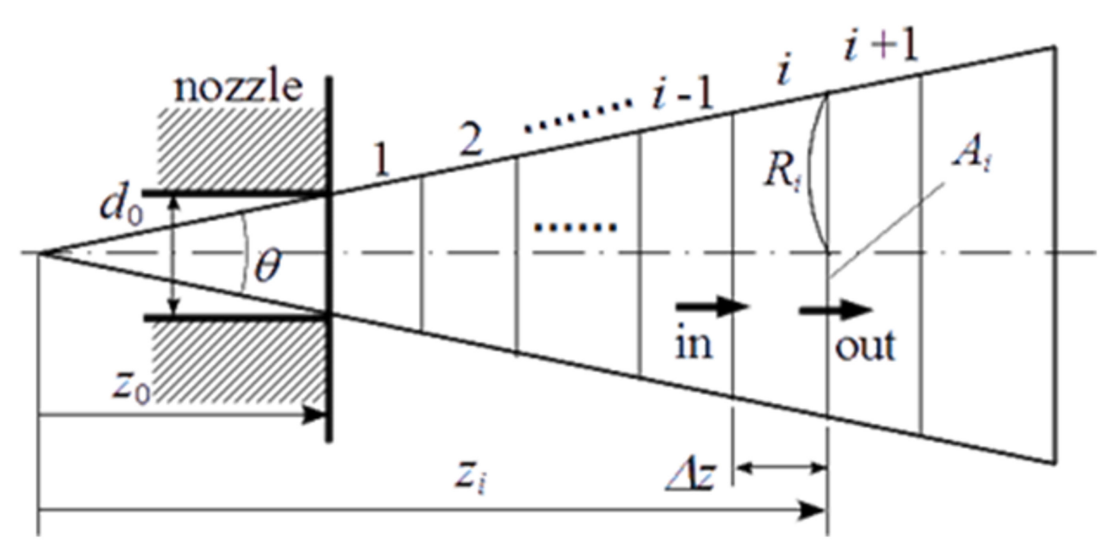

Figure 1. Schematic diagram of one-dimensional discrete diesel spray model.

\subsection{Varying Injection Rate Calculation}

Boundary conditions for solving these equations above are according to Equations (9) and (10):

$$
\begin{gathered}
\overline{\overline{\mathrm{u}}}_{0}(t)=u_{\mathrm{f}}(t) \\
\overline{\overline{\mathrm{X}}}_{\mathrm{f}, 0}(t)=1
\end{gathered}
$$

where the subscript " 0 " means the inlet surface of the first control volume, i.e., the nozzle exit. $u_{\mathrm{f}}(t)$ is a cross-section averaged fuel velocity at the nozzle exit and is calculated by Equation (11):

$$
u_{\mathrm{f}}(t)=\frac{\dot{m}_{\mathrm{f}, 0}(t)}{\rho_{\mathrm{f}} \cdot \mu \cdot \pi \cdot d_{\mathrm{n}}^{2} / 4}
$$

where $\dot{m}_{\mathrm{f}, 0}(t)$ is the injection mass rate, $\mu$ is the flow coefficient of the nozzle orifice, $d_{\mathrm{n}}$ is the geometric orifice diameter. 
$\dot{m}_{\mathrm{f}, 0}(t)$ is assumed to have a trapezoidal pattern, as shown in Figure 2, and it can be calculated according to Equation (12).

$$
\dot{m}_{\mathrm{f}, 0}(t)= \begin{cases}\dot{m}_{\mathrm{f}, \max } \cdot t / \Delta t_{r} & \left(0 \leq t<\Delta t_{r}\right) \\ \dot{m}_{\mathrm{f}, \max } & \left(\Delta t_{r} \leq t<\Delta t_{\mathrm{js}}\right) \\ \dot{m}_{\mathrm{f}, \max } \cdot\left[1-\left(t-\Delta t_{\mathrm{js}}\right) / \Delta t_{d}\right] & \left(\Delta t_{j s} \leq t<\Delta t_{j s}+\Delta t_{d}\right) \\ 0 & \left(\Delta t_{\mathrm{js}}+\Delta t_{d} \leq t\right)\end{cases}
$$

where the injection mass rate peak $\dot{m}_{\mathrm{f}, \max }$ is obtained by Equation (13):

$$
\dot{m}_{\mathrm{f}, \max }=m_{\mathrm{f}, \mathrm{total}} /\left[\Delta t_{\mathrm{js}}+\left(\Delta t_{d}-\Delta t_{r}\right) / 2\right]
$$

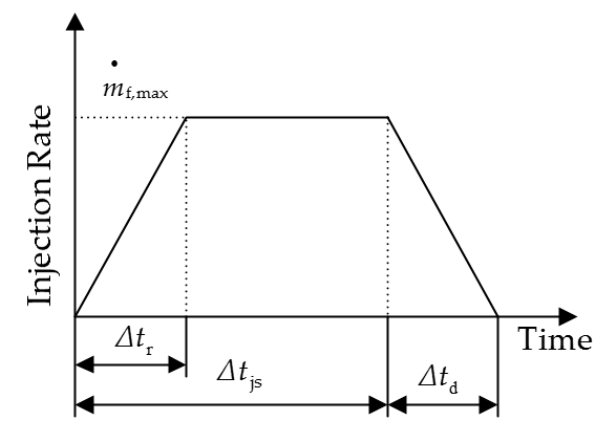

Figure 2. Injection rate pattern.

\section{Results and Discussion}

\subsection{Validation of the Spray Model with Short Injection Duration}

For model validation, the diesel spray tip penetration even after EOI with short injection duration was calculated and compared with the shadowgraph data of non-combusting diesel sprays in a constant volume chamber. The experimental setup and measuring equipment are the same as that in our previous study [11]. The constant volume chamber is in cylindrical shape with a volume of 150 $\mathrm{cm}^{3}$. Its diameter and depth are $80 \mathrm{~mm}$ and $30 \mathrm{~mm}$, respectively. In the shadowgraph imaging system, a Xeon lamp is used as the light source. The focal lengths of the two same concave mirrors used are $1910 \mathrm{~mm}$. The high-speed camera has a shooting speed of 50,000 fps and the exposure time was $5 \mathrm{~ms}$. With the aid of a common-rail injection system, an advanced injector with a discharge coefficient of 0.8 is employed to inject diesel fuel into the chamber. The operating conditions are listed in Table 1 , and the calculation was also performed based on these conditions.

Table 1. Calculation conditions for validation.

\begin{tabular}{cc}
\hline Items & Parameters \\
\hline Ambient pressure & $4.0 \mathrm{MPa}$ \\
Ambient temperature & $1015 \mathrm{~K}$ \\
Fuel & $\mathrm{JIS} 2 \#$ \\
Cetane number & 54.2 \\
Fuel density at $15^{\circ} \mathrm{C}$ & $832.7 \mathrm{~kg} / \mathrm{m}^{3}$ \\
Ignition temperature & $72.0^{\circ} \mathrm{C}$ \\
Dynamic viscosity at $30^{\circ} \mathrm{C}$ & $3.431 \mathrm{~mm} / \mathrm{s}$ \\
Calorific value & $45.82 \mathrm{MJ} / \mathrm{kg}$ \\
Injection pressure & $180 \mathrm{MPa}$ \\
Injection quantity & $2.5 \mathrm{mg}, 5.0 \mathrm{mg}$ \\
\hline
\end{tabular}


Table 1. Cont.

\begin{tabular}{cc}
\hline Items & Parameters \\
\hline Injection duration & $0.175 \mathrm{~ms}, 0.297 \mathrm{~ms}$ \\
Nozzle diameter & $0.18 \mathrm{~mm}$ \\
Nozzle holes number & 6 \\
Ambient gas composition by volume before injection & $\mathrm{O}_{2}: 0.5 \%, \mathrm{~N}_{2}: 87.4 \%, \mathrm{CO}_{2}: 4.8 \%, \mathrm{H}_{2} \mathrm{O}: 7.3 \%$ \\
\hline
\end{tabular}

Figure 3 shows the comparison of spray tip penetrations between the simulation result and the experiment data from shadowgraph with the injection quantity of $0.417 \mathrm{mg}$ and $0.833 \mathrm{mg}$ for single nozzle hole under $180 \mathrm{MPa}$ injection pressure, respectively. The spray tip penetrations and time are expressed on a logarithmic scale. As the injection rates in Figure 3 show, the actual injection rates have a shape like a triangle, therefore the calculations were based on the triangle injection rate and the injection durations were kept the same with that of the measurements. The results reveal that the simulation results are slightly smaller than the experiment data, which can be ascribed to the slightly lower measurement accuracy of injection rate and spray tip penetration under a very small amount of fuel injected, especially in the initial injection period. The simplification of the triangle injection rate for simulation further increases such a difference. However, the simulation results of spray tip penetration show similar tendencies to the measured data. Furthermore, the spray penetrations are able to capture the relation of square-root dependence on time around the moment of twice the injection duration. Then the spray penetrations change to the relation of fourth-root dependence on time. This phenomenon is coherent with that affected by the entrainment wave [24]. Thus, it is reasonable to apply this spray model to analyze the diesel spray mixing process.

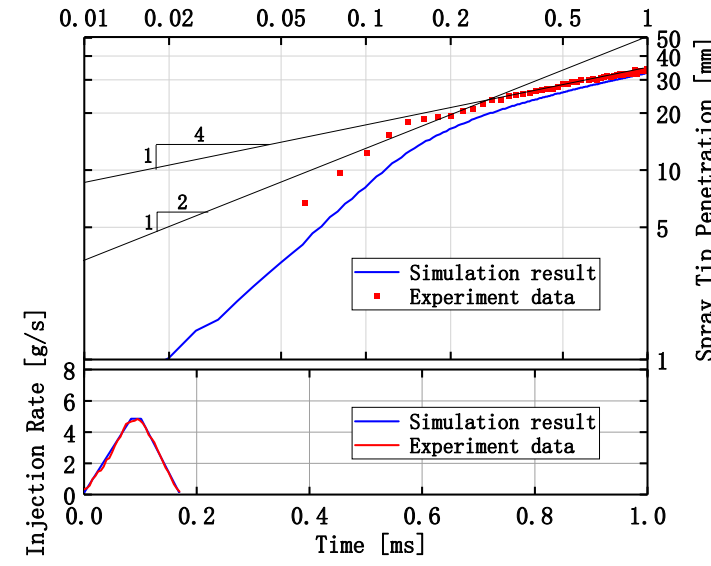

(a)



(b)

Figure 3. Comparison of spray tip penetrations between the simulation result and experiment data under (a) the injection quantity of $0.417 \mathrm{mg}$ and (b) injection quantity of $0.833 \mathrm{mg}$.

\subsection{Calculation of Spray Tip Penetrations Under Varying Injection Rate}

As has been found in a previous study [19], the ramping-up and ramping-down injection rate shapes both have a significant influence on FPEG. Due to the similarity between FPEG and the conventional diesel engine, these two injection rate shapes must also play an important role in the latter. However, there is little relative research about this. Inversely, as the common used and typical injection rate shapes in diesel engines, scholars have devoted a great deal of effort to the triangle and rectangle as well as trapezoid shapes [9-13]. In order to compare the potential of varying injection rate shapes to lower the pollutant emissions of diesel engines more objectively and comprehensively and find the optimized injection strategy, five injection rate shapes (including triangle, ramping-up, ramping-down, rectangle and trapezoid) were selected in this paper, as shown in Figure 4. To simulate the diesel spray 
propagation under the conditions extant in engines' cylinders, the ambient gas conditions are set as the actual in-cylinder pressure and temperature, so the calculation conditions are the same as given in Table 1, and the injection rates have been shown in a previous study [11].

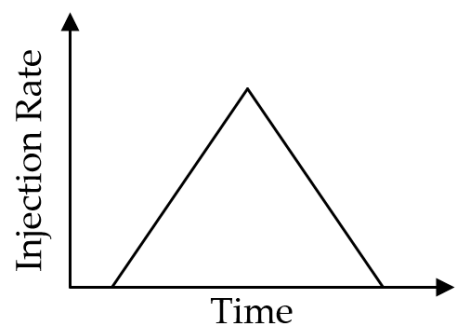

(a)

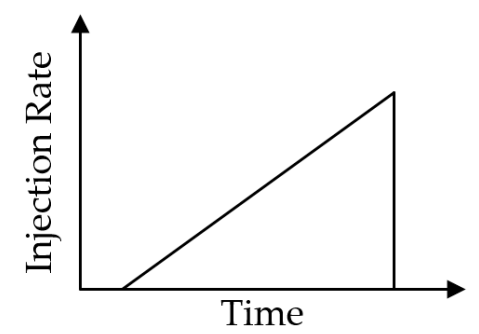

(b)

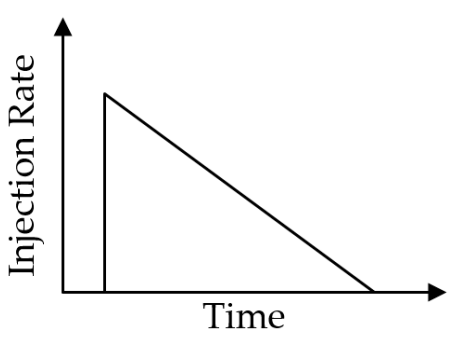

(c)

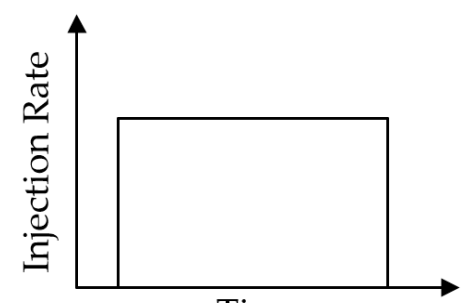

Time

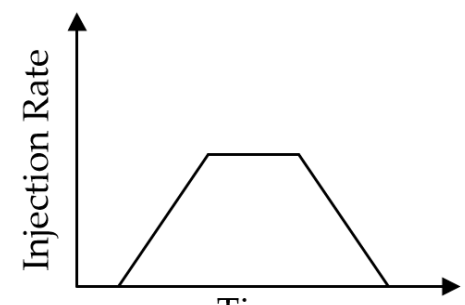

Time

(d)

(e)

Figure 4. Schematic diagram of five injection rate shapes: (a) Triangle; (b) Ramping-up; (c) Ramping-down; (d) Rectangle; (e) Trapezoid.

Figure 5 shows the spray tip penetrations with the injection quantity of $0.417 \mathrm{mg}$ and $0.833 \mathrm{mg}$ for a single nozzle hole, respectively. Both Figure $5 a, b$ reveal the same tendency that the initial spray tip penetration depends on the injection rate. A higher injection rate leads to a larger spray tip penetration during the initial injection.

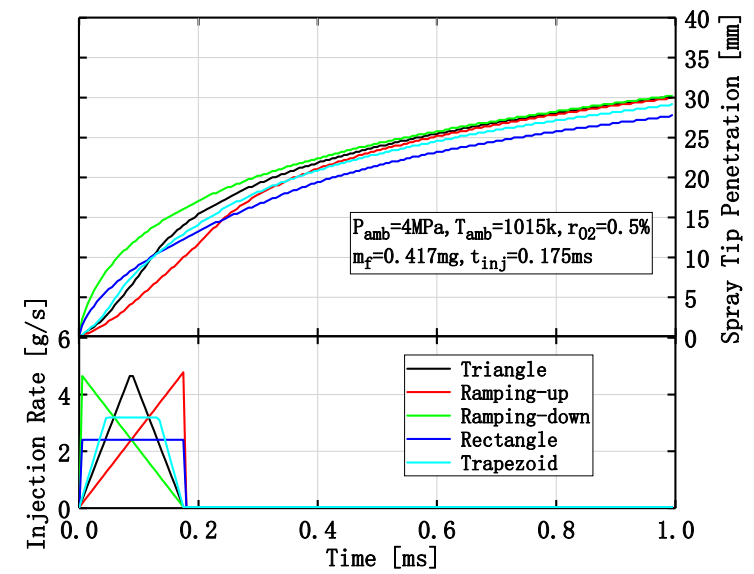

(a)



(b)

Figure 5. Spray tip penetration under (a) the injection quantity of $0.417 \mathrm{mg}$ and (b) injection quantity of $0.833 \mathrm{mg}$ NOTE. $\mathrm{P}_{\mathrm{amb}}$ : ambient pressure; $\mathrm{T}_{\mathrm{amb}}$ : ambient temperature; $\mathrm{r}_{\mathrm{O} 2}$ : volume fraction of $\mathrm{O}_{2}$ in the ambient gas; $\mathrm{m}_{\mathrm{f}}$ : injection quantity of fuel for single nozzle hole; $\mathrm{t}_{\text {inj: }}$ injection duration.

A higher maximum injection rate finally leads to a larger spray tip penetration, which is different from the previous study [19] and can be seen from two aspects. On the one hand, the triangle, ramping-up and ramping-down injection rate shapes have the same maximum injection rate, although their spray tip penetrations evolve with different growth rates in the early injection duration, they all 
gradually tend to the same penetration value and slope over time. On the other hand, compared with the rectangle and trapezoid injection rate shapes, the triangle injection rate reaches the larger spray tip penetration finally due to its higher maximum injection rate though its injection rate is smaller than that of the other two during the initial injection. However, in spite of the fact that the triangle and ramping-up as well as ramping-down injection rate shapes reach the final same spray penetration, the ramping-down injection rate has been keeping the greater spray tip penetration until the differences between them can be ignored, meaning that its overall spray gets more time to mix with air. Therefore, the ramping-down injection rate shape could obtain the better fuel-air mixing if the ignition delay is long enough.

\subsection{Analysis of Entrainment Rates Under Varying Injection Rate}

One of the indicators that allow for the insightful analysis on mixing process of diesel spray is the entrainment rate. Figure 6 shows the entrainment rates with varying injection rate shapes. Comparing the entrainment rates for the same injection rate shape under different fuel injection quantity, the larger fuel injection quantity case (Figure $6 \mathrm{~b}$ ) visibly gets much higher entrainment rate, with the variation tendency extremely similar to the smaller fuel injection quantity case (Figure 6a). For the same fuel injection quantity, it can be found that the higher injection rate causes the higher entrainment rate during the initial injection. Each injection rate shape has the special entrainment rate pattern and the entrainment rate comes to the peak soon after EOI. The entrainment rate peaks (from large to small) are in the order: ramping-up, triangle, trapezoid, ramping-down and rectangle. It is the entrainment wave after EOI that should be responsible for such difference.

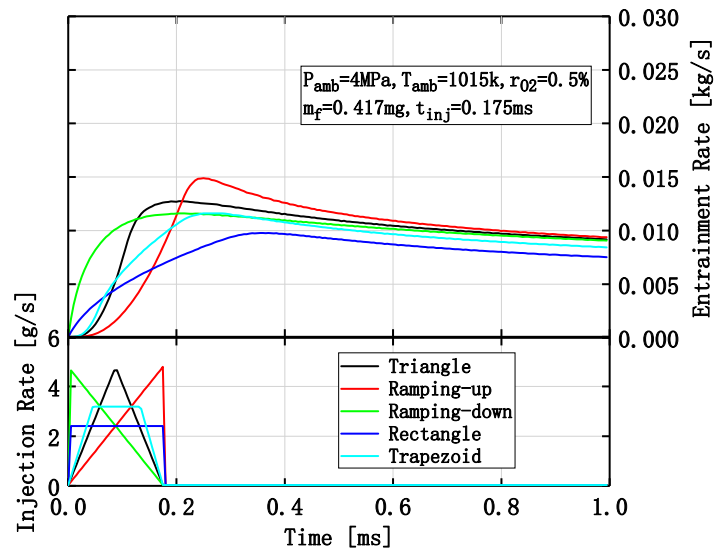

(a)



(b)

Figure 6. Entrainment rate under (a) the injection quantity of $0.417 \mathrm{mg}$ and (b) injection quantity of $0.833 \mathrm{mg}$.

As discussed in the previous study [2], the velocity at the nozzle exit is high enough to affect the spray when the injection rate just begins to decrease for the ramping-down, triangle and trapezoid injection rates. Once the velocity at the nozzle exit is too low to affect the spray, the real time of the $\mathrm{EOI}\left(t_{\mathrm{EOI}}\right)$ can be defined. $t_{\mathrm{EOI}}$ is the start of entrainment wave and the velocity at the nozzle exit at $t_{\mathrm{EOI}}\left(U_{\mathrm{EOI}}\right)$ determines the spray penetration level. In fact, the peak of entrainment rate occurs when the entrainment wave arrives at the spray tip. Thus, the entrainment rate peak is decided by $t_{\mathrm{EOI}}$ and $U_{\mathrm{EOI}}$. To calculate $t_{\mathrm{EOI}}$ and $U_{\mathrm{EOI}}$ under varying injection rate shapes, the Equation (14) proposed by Liu et al. [11] is used in this paper:

$$
\mathrm{U}_{\mathrm{EOI}}=\left(1-R_{\mathrm{IV}} \cdot t_{\text {decay }} / t_{\mathrm{inj}}\right) \cdot u_{\max }
$$


where $R_{\mathrm{IV}}$ is a dimensionless ratio and is selected to be 0.65 in this paper, $t_{\text {decay }}$ is the period that injection velocity decays, $t_{\text {inj }}$ is the injection duration, $\mathrm{u}_{\max }$ is the maximum injection velocity.

The calculation results of $t_{\mathrm{EOI}}$ and $U_{\mathrm{EOI}}$ for the injection quantity of $0.417 \mathrm{mg}$ and $0.833 \mathrm{mg}$ are shown in Tables 2 and 3 respectively. $t_{\text {peak }}$ denotes the time at the entrainment rate peak.

Table 2. Calculation results of $t_{\mathrm{EOI}}$ and $U_{\mathrm{EOI}}$ for injection quantity of $0.417 \mathrm{mg}$.

\begin{tabular}{cccc}
\hline Injection Rate Shape & $\boldsymbol{t}_{\text {EOI }}(\mathbf{m s})$ & $\boldsymbol{U}_{\text {EOI }}(\mathbf{m} / \mathbf{s})$ & $\boldsymbol{t}_{\text {peak }}(\mathbf{m s}) \mathbf{2} \cdot \boldsymbol{t}_{\text {EOI }}(\mathbf{m s})$ \\
\hline Triangle & 0.116 & 188.12 & $0.21 / 0.232$ \\
Ramping-up & 0.175 & 278.70 & $0.25 / 0.35$ \\
Ramping-down & 0.1138 & 97.55 & $0.215 / 0.2276$ \\
Rectangle & 0.175 & 139.30 & $0.355 / 0.35$ \\
Trapezoid & 0.1401 & 156.74 & $0.265 / 0.2802$ \\
\hline
\end{tabular}

Table 3. Calculation results of $t_{\mathrm{EOI}}$ and $U_{\mathrm{EOI}}$ for injection quantity of $0.833 \mathrm{mg}$.

\begin{tabular}{cccc}
\hline Injection Rate Shape & $\boldsymbol{t}_{\text {EOI }}(\mathbf{m s})$ & $\boldsymbol{U}_{\text {EOI }}(\mathbf{m} / \mathbf{s})$ & $\boldsymbol{t}_{\text {peak }}(\mathbf{m s}) \mathbf{2} \cdot \boldsymbol{t}_{\text {EOI }}(\mathbf{m s})$ \\
\hline Triangle & 0.195 & 219.92 & $0.355 / 0.39$ \\
Ramping-up & 0.297 & 325.80 & $0.42 / 0.594$ \\
Ramping-down & 0.195 & 114.03 & $0.385 / 0.39$ \\
Rectangle & 0.297 & 165.00 & $0.595 / 0.594$ \\
Trapezoid & 0.23 & 183.34 & $0.42 / 0.46$ \\
\hline
\end{tabular}

A same law can be discovered from Tables 2 and 3, that is, $t_{\text {peak }}$ in the other four injection rate shapes, except the ramping-up, is almost twice that of $t_{\mathrm{EOI}}$, which is because the entrainment wave travels downstream at twice the initial spray penetration rate. As reference [24] demonstrated, the typical phenomenon is revealed in the case of rectangle injection rate, the diesel jet with rectangle injection rate can be treated as a steady jet, and the entrainment wave front arrives at the jet tip at twice of injection duration. Figure 7 shows the mean velocity over the cross-sectional area against the axial position in the diesel spray under five injection rate shapes with time varying. As shown in Figure $7 \mathrm{~d}$ (rectangle injection rate), the same axial position has the same velocity during injection due to the steady state. There is an envelope velocity curve for the steady spray, and the velocity at the position that belong to the spray steady part after EOI is on the envelope velocity curve. After the entrainment wave front arriving at the spray tip, the total spray transfers to the decelerating state, which causes the velocities at any axial position are lower than that of steady state.

For the trapezoid injection rate, the constant injection rate takes main injection process, so that the spray can be treated as the steady state. According to the previous study [11], the twice of $t_{\mathrm{EOI}}$ is close to the $t_{\text {peak }}$. As shown in Figure 7e, the envelope velocity curve starts from the steady part and it extends to the $t_{\text {peak }}$. After $t_{\text {peak }}$, the spray gets into the decelerating state. In Figure $7 \mathrm{c}$, although the spray is not in the steady state due to the ramping-down injection rate, the spray tip velocities at different time before $t_{\text {peak }}$ are on the same envelope velocity curve. After $t_{\text {peak }}$, the spray tip velocities depart from the envelope velocity curve, and the values are lower than that on the envelope curve. It might be reasonable to use the twice of $U_{\mathrm{EOI}}$ to represent the average entrainment wave speed, and the $U_{\mathrm{EOI}}$ can be treated as the average effective fuel injection velocity that considers the fuel penetration as the spray penetration. Then the $t_{\text {peak }}$ is similar with twice of $t_{\mathrm{EOI}}$ even for the unsteady spray with ramping-down injection rate.

However, because the momentum flux at each axial position of spray needs a certain response time to the change of the injected velocity, the velocities at some positions still increase even the injection velocity turns to decrease or stop, which can be found in Figure 7a,b. In Figure 7a, the envelope velocity curve can cover the spray tip velocity up to $t_{\text {peak }}$ from $0.16 \mathrm{~ms}$. That means the injection velocity increase effect has been reached spray tip, the decrease of injection velocity effect mainly control the 
spray. Meanwhile, the $t_{\text {peak }}$ is almost equal to the twice of $t_{\mathrm{EOI}}$, which is indicated the effectiveness of the average entrainment wave and spray penetration speed concept.

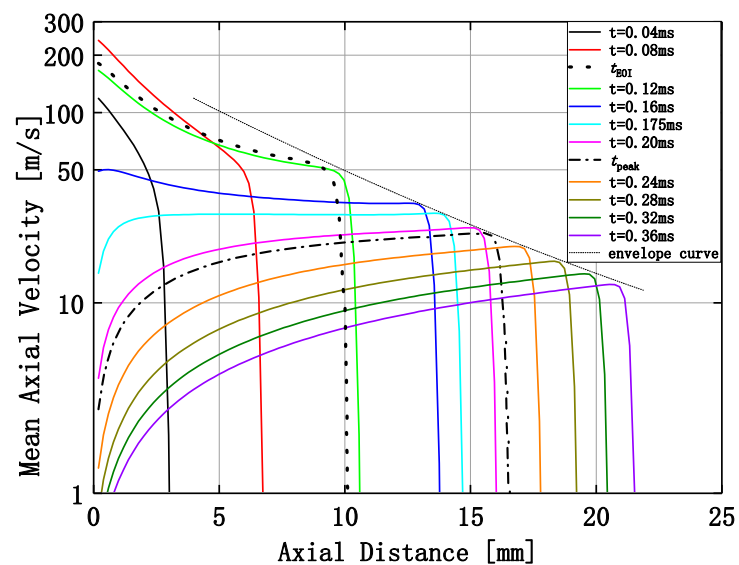

(a)

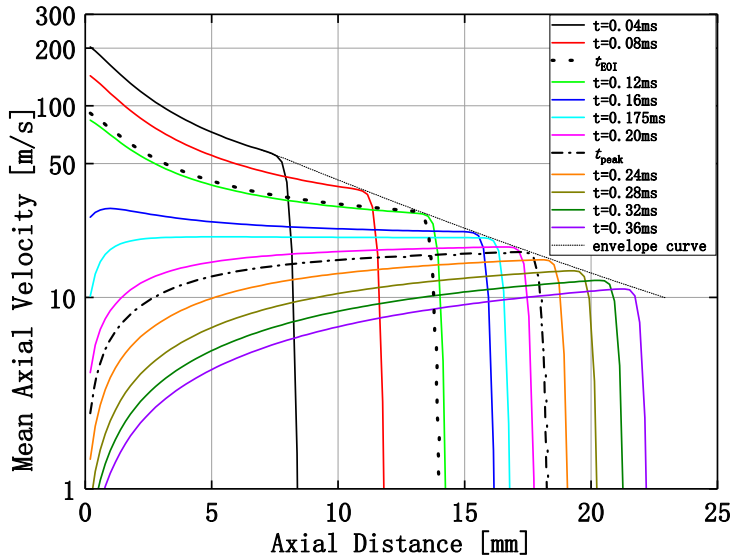

(c)

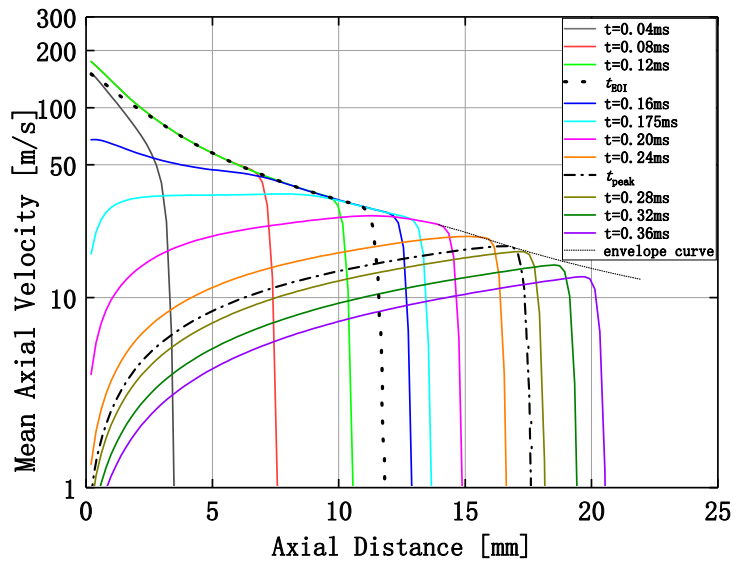

(e)



(b)

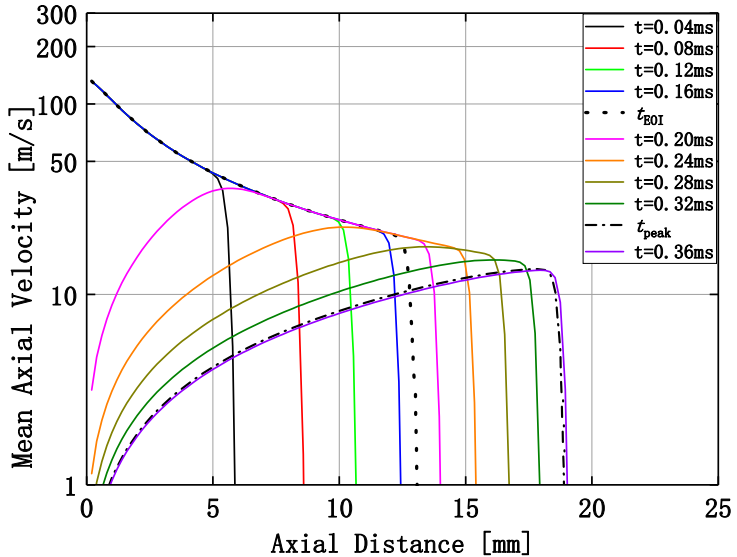

(d)

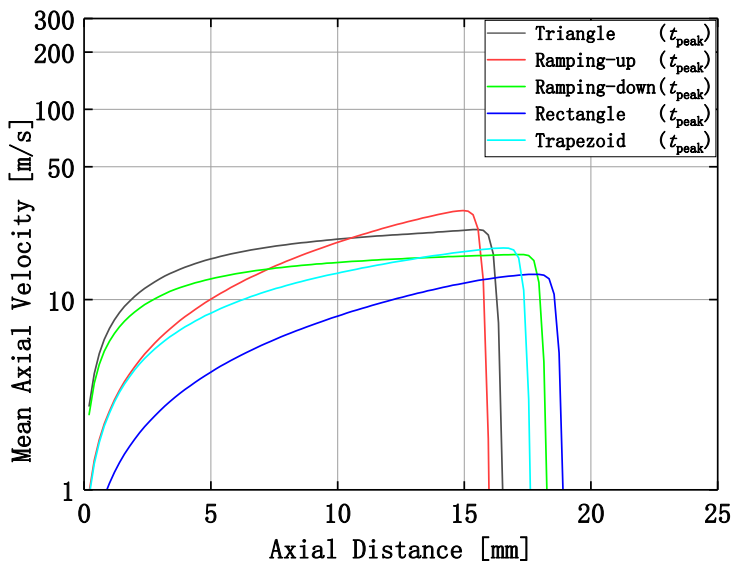

(f)

Figure 7. Mean axial velocity under five injection rate shapes: (a) Triangle; (b) Ramping-up; (c) Ramping-down; (d) Rectangle; (e) Trapezoid and (f) Comparison at $t_{\text {peak }}$.

Regarding the ramping-up injection rate, there is no steady-like state as shown in Figure $7 \mathrm{~b}$, because the injection rate is reduced to zero sharply. At the $t_{\mathrm{EOI}}$, the $U_{\mathrm{EOI}}$ is the maximum injection velocity, the average entrainment wave speed can be calculated by twice of $U_{\mathrm{EOI}}$. However, the increase 
of the injection velocity effect has not traveled to spray tip, and the $U_{\mathrm{EOI}}$ cannot represent the average spray penetration speed. Similar to the assumption of Liu et al. [11], a same parameter $R_{\mathrm{IV}}(0.65)$ is selected in this paper as a factor of $U_{\mathrm{EOI}}$ to calculate the average fuel penetration speed, which represents the average spray penetration speed and one third of average entrainment wave speed. As shown in Equation (15), $t_{1}$ is the duration from the $t_{\mathrm{EOI}}$ to the time of entrainment wave reaching the spray tip:

$$
2 \cdot U_{\mathrm{EOI}} \cdot t_{1}=0.65 \cdot U_{\mathrm{EOI}} \cdot\left(t_{\mathrm{EOI}}+t_{1}\right)
$$

Equation (16) can be simplified as:

$$
3 \cdot U_{\mathrm{EOI}} \cdot t_{1}=U_{\mathrm{EOI}} \cdot\left(t_{\mathrm{EOI}}+t_{1}\right)
$$

then the following expression is obtained:

$$
t_{1}=0.5 \cdot t_{\mathrm{EOI}}
$$

Thus, the entrainment wave arrives at the spray tip at $t=1.5 t_{\mathrm{EOI}}$, which is consistent with the calculation result of $t_{\text {peak }}$ and $t_{\mathrm{EOI}}$ under the ramping-up injection rate, $t_{\text {peak }}(0.25 \mathrm{~ms})$ is about 1.5 times $(0.2625 \mathrm{~ms})$ of $t_{\mathrm{EOI}}$ for the injection quantity of $0.417 \mathrm{mg}$, while $t_{\text {peak }}(0.42 \mathrm{~ms})$ is also about 1.5 times $(0.4455 \mathrm{~ms})$ of $t_{\mathrm{EOI}}$ for the injection quantity of $0.833 \mathrm{mg}$. In addition, as shown in Figure $7 \mathrm{~b}$, the entrainment wave takes $0.075 \mathrm{~ms}$ to arrive at the spray tip with the spray penetration of $15.8 \mathrm{~mm}$ at $0.25 \mathrm{~ms}$. The average entrainment wave traveling speed is $210.67 \mathrm{~mm} / \mathrm{ms}$, and the average spray penetration rate is about $63.2 \mathrm{~mm} / \mathrm{ms}$. The average entrainment wave traveling speed is 3.33 times of the average spray penetration rate, which is similar with the result calculated using the $U_{\mathrm{EOI}}$.

Moreover, due to the largest $U_{\mathrm{EOI}}$, the spray of ramping-up injection rate penetrates fast after EOI, compared with the triangle and ramping-down injection rates (Figure 5), so the terminal spray penetration is a combined effect result of injection rate before EOI and $U_{\mathrm{EOI}}$. The triangle, ramping-up and ramping-down injection rate shapes tend to the same spray penetration finally just because an opportune tradeoff is reached.

As shown in Figure 7, there are some similarities between five injection rate shapes: the mean axial velocity decreases along the axial distance before EOI and increases along the axial distance after EOI, but the velocity gradients are different. When fuel injection supply stops after EOI, the mass conservation and continuity theorem require a fast gas entrainment to compensate for the decreasing fuel mass flux. Therefore, the fuel mass flux, or speaking directly, the velocity gradient determines the intensity of entrainment wave. As mentioned above, the entrainment rate peak occurs when the entrainment wave arrives at the spray tip and $t_{\text {peak }}$ is decided by $t_{\mathrm{EOI}}$ as well as the speed of entrainment wave. In order to explain the difference of entrainment rate peak for five injection rate shapes, the velocity gradient at $t_{\text {peak }}$ should be taken into account. Shown in Figure $7 \mathrm{f}$, it is obvious that five injection rate shapes have different velocity gradients and velocity magnitude at $t_{\text {peak }}$. Because the entire spray has been enhanced by the entrainment wave at this moment, associated with the cone structure of spray, the entrainment effect of downstream spray accounts for a larger proportion of the entire spray due to its larger volume. Thus, the ramping-up injection rate has the highest velocity gradient and the fast mean axial velocity in downstream, which leads to the biggest entrainment rate peak in Figure 6, followed by the triangle injection rate. The trapezoid injection rate gets the slightly larger entrainment rate peak than the ramping-down on account of its higher velocity gradient, too. While for the rectangle injection rate, its velocity gradient and velocity magnitude are both the lowest, resulting in a much weaker entrainment effect than the other four injection rate shapes, so its entrainment rate peak is the lowest. 


\subsection{Analysis of Mixing Process Based on Equivalence Ratios}

Spray tip penetration and entrainment rate can estimate the diesel spray mixing process in the macroscopic view. However, the microscopic mixing process is also a very significant factor for diesel spray combustion. To analyze the microscopic mixing process, the equivalence ratio along the spray axial position with varying time was calculated using the spray model. Figure 8 shows the equivalence ratio distributions under five injection rate shapes. Figure $8 \mathrm{a}, \mathrm{c}, \mathrm{e}$ show the similar equivalence ratio level after EOI in the cases of triangle, ramping-down as well as trapezoid injection rates, the equivalence ratio is almost evenly distributed along the spray axial distance after EOI.

Especially at the time of $0.36 \mathrm{~ms}$, the equivalence ratio is around 1.0. The fuel could be burned completely if the ignition occurred at that time, as well as there is no enough $\mathrm{O}_{2}$ remained for $\mathrm{NO}_{\mathrm{x}}$ formation. Therefore, the fuel consumption and $\mathrm{NO}_{\mathrm{x}}$ emission can decrease simultaneously. But compared with the triangle and trapezoid injection rates, the ramping-down is able to reach much longer spray penetration before EOI, while the downstream spray has lower equivalence ratio, indicating a stronger mixing process. So the ramping-down injection rate has an advantage over the other two in creating homogeneous mixture. However, due to the low velocity near the nozzle exit, the fuel-rich mixture formation near the nozzle exit, it usually leads to the high soot formation.

Figure 8 b,d show the similar results of equivalence ratio along the spray axial distance with varying time in the cases of ramping-up and rectangle injection rates, the mixture near the nozzle exit quickly gets leaner after EOI, and the equivalence ratio increases with the axial distance increasing. It means that the both two injection rates with longer ignition delay can decrease the soot formation near the nozzle exit on certain conditions. It can be observed that the ramping-up injection rate obtains much leaner mixture than that of rectangle injection rate after EOI. This phenomenon indicates that the ramping-up injection rate is a better choice to realize LTC, because the ignition is occurred after EOI (with the overlong ignition delay not considered). In summary, the spray characteristics among the penetration and entrainment rate as well as equivalence ratio under varying injection rate shapes can be synoptically shown in Table 4, where I to V denote the maximum to the minimum of each parameter. From the practical point of view, these spray characteristics can provide some important guidance and reference. For example, the long penetration is always expected in the low-speed diesel engine with big bore and long stroke, so the ramping-down injection rate is an optimal choice. Instead, the spray-wall impingement process is tried to be avoided sometimes, hence a relatively short penetration is needed and the rectangle injection rate should be taken into account first. In some advanced combustion modes, such as PCCI and LTC, the ramping-up injection rate can be used to greatly promote the mixing of fuel and the cold ambient air or exhaust gas, then quickly decrease the temperature of mixture as well as the formation of $\mathrm{NO}_{\mathrm{x}}$. As for homogeneous charge compression ignition (HCCI), the uniform charge in cylinder is indispensable, so that all points in diesel spray are ignited at the same time and the heat is evenly distributed throughout the cylinder. In this way, the triangle, ramping-down as well as trapezoid injection rates are the theoretically feasible alternatives because the equivalence ratio is almost evenly distributed along the spray axial distance after EOI in these cases.

Table 4. Comparison of spray characteristics under varying injection rate shapes.

\begin{tabular}{cccc}
\hline $\begin{array}{c}\text { Injection Rate } \\
\text { Shape }\end{array}$ & $\begin{array}{c}\text { Penetration } \\
\text { After EOI }\end{array}$ & $\begin{array}{c}\text { Entrainment Rate } \\
\text { Peak }\end{array}$ & $\begin{array}{c}\text { Equivalence Ratio } \\
\text { Near Nozzle }\end{array}$ \\
\hline Triangle & II & II & II \\
Ramping-up & III & I & V \\
Ramping-down & I & IV & I \\
Rectangle & V & V & IV \\
Trapezoid & IV & III & III \\
\hline
\end{tabular}




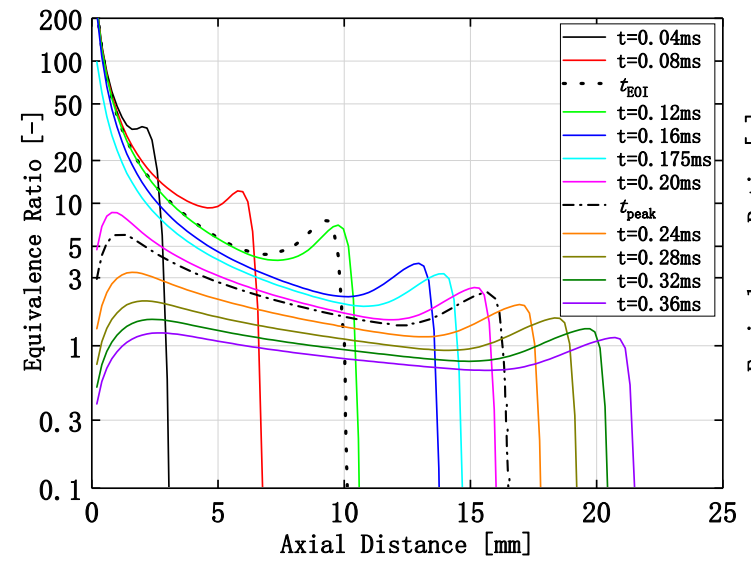

(a)

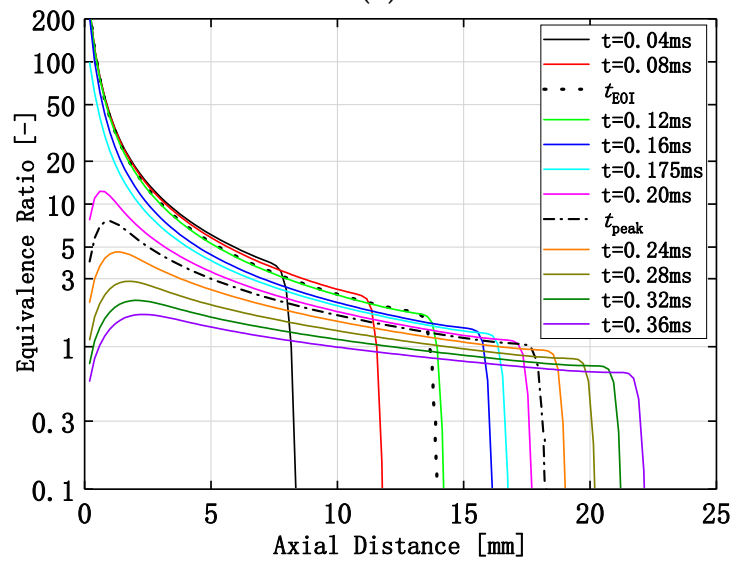

(c)

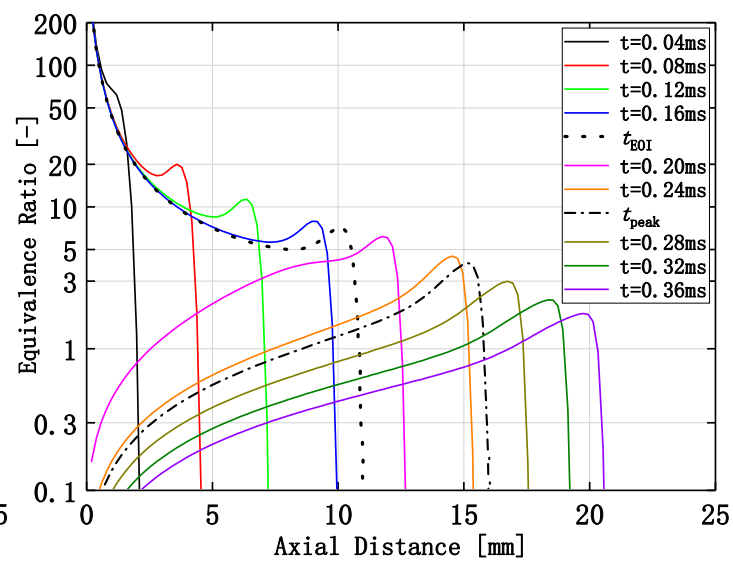

(b)

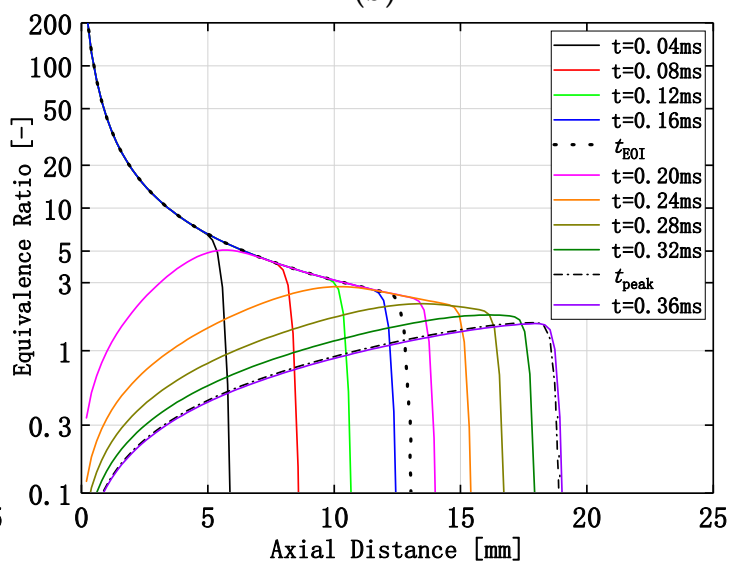

(d)

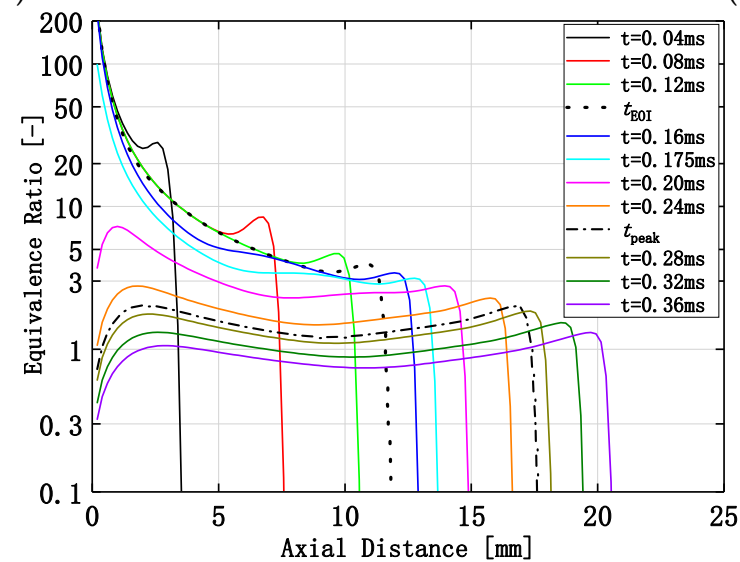

(e)

Figure 8. Equivalence ratio after EOI under five injection rate shapes: (a) Triangle; (b) Ramping-up; (c) Ramping-down; (d) Rectangle; (e) Trapezoid.

\subsection{Effect of the Multiple-Injection}

According to the information in Table 4, the ramping-down injection rate could reach the longest penetration but also the highest equivalence ratio near the nozzle, while the ramping-up injection rate obtains the largest entrainment rate peak and the lowest equivalence ratio near the nozzle. So it is a good idea to develop a new multiple-injection strategy that both contains the ramping-down and ramping-up injection rates. Figure 9 shows the comparisons of spray tip penetration and entrainment rate between the ramping-down single injection and the multiple-injection. In Figure 9a, the spray tip penetration of the multiple-injection is equal to that of the ramping-down single injection before 
$t=0.1 \mathrm{~ms}$. After that, the spray tip penetration of the multiple-injection becomes smaller than that of the ramping-down single injection due to the sharply decrease of injection rate. As shown in Figure $9 b$, although the entrainment rate of the multiple-injection is smaller than that of the ramping-down single injection from $t=0.05 \mathrm{~ms}$ to $t=0.3 \mathrm{~ms}$, it increases rapidly over the latter after $t=0.3 \mathrm{~ms}$ because the ramping-up sub-injection begins to play a leading role in the entrainment process.

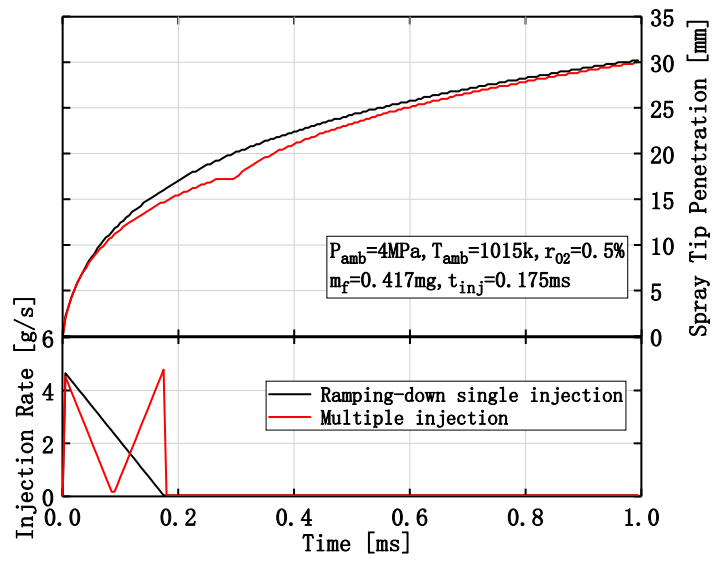

(a)



(b)

Figure 9. Comparisons of spray tip penetration (a) and entrainment rate (b) between the ramping-down single injection and the multiple-injection.

Figure 10 shows the comparison of entrainment rate after EOI between the multiple-injection and the ramping-down single injection. The spray head of the multiple-injection is a little shorter than that of the ramping-down single injection, which is in agreement with Figure $9 \mathrm{a}$. When it is at $t=0.18 \mathrm{~ms}$ and $t=0.24 \mathrm{~ms}$, since the sub-spray generated by the ramping-up sub-injection has not overtaken the sub-spray generated by the ramping-down sub-injection, and much fuel accumulates in the former spray head, so the high-concentration fuel causes little gas to be entrained. Due to the slower injection velocity, the entrainment rate of the ramping-down sub-injection in the multiple-injection is smaller than that of the ramping-down single injection even though they have the similar injection rate shape. However, the upstream sub-spray generated by the ramping-up sub-injection of the multiple-injection has much higher entrainment rate than that of the ramping-down single injection. After $t=0.24 \mathrm{~ms}$, the upstream sub-spray overtakes the downstream sub-spray. Because the entrainment wave of the ramping-up sub-injection plays a dominant role in the whole spray, the entrainment rate of the multiple-injection is much higher than that of the ramping-down single injection, indicating that the multiple-injection can get better mixing effect.

Figure 11 shows the comparisons of equivalence ratio after EOI between the multiple-injection and the ramping-down single injection. In the multiple-injection case, the equivalence ratio after EOI remains the characteristic of ramping-up injection rate shape, resulting from the major influence of the ramping-up sub-injection. The variation of equivalence ratio of the multiple-injection is seen to be quite different from the ramping-down single injection. The equivalence ratio of the multiple-injection is much lower near the nozzle exit and increases gradually along the axial distance. In addition, it is obvious that the spray tail of the multiple-injection moves downstream quickly, while the ramping-down single injection consistently keeps the high equivalence ratio near the nozzle exit. Therefore, the multiple-injection is beneficial to improve the working environment of the nozzle and decrease the soot emission. 


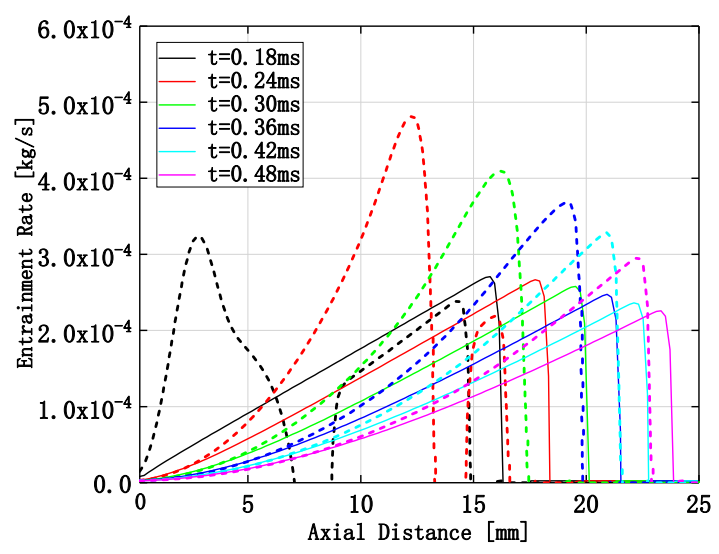

Figure 10. Comparisons of entrainment rate after EOI between the ramping-down single injection and the multiple-injection (solid lines: ramping-down single injection; dotted lines: multiple-injection).



Figure 11. Comparisons of equivalence ratio between the ramping-down single injection and the multiple-injection (solid lines: ramping-down single injection; dotted lines: multiple-injection).

\subsection{Effect of the Gas-Jet After EOI}

However, incomplete combustion will occur in the fuel-lean zone if the equivalence ratio is too low, so the originality of combining the ramping-down and ramping-up injection rates to optimize the working conditions of the nozzle and emission performance still has some limitations. To overcome the problem, another improvement approach is presented in this paper.

The main idea of the new method is to use the gas-jet after EOI to blow the mixture near the nozzle exit downstream under the ramping-down injection rate shape, as shown in Figure 12. In this way, the stagnant fuel near the nozzle exit due to the influence of entrainment wave could be carried by the gas-jet to join in the combustion of downstream spray, which can not only improve the working conditions of the nozzle, but also decrease the soot emission.

This paper studied the influence of gas jet with two different velocities on the spray evolution, the selected gas-jet velocities $(100 \mathrm{~m} / \mathrm{s}, 200 \mathrm{~m} / \mathrm{s})$ are both lower than the local speed of sound $(648.89 \mathrm{~m} / \mathrm{s})$, so the influence of shock wave is inexistent. The calculation conditions for gas-jet are listed in Table 5 . The comparisons of spray tip penetration and entrainment rate between the ramping-down injection without gas-jet and the ramping-down injection with gas-jet are shown in Figure 13. It seems that whether there is gas-jet after EOI or not has no effect on the spray tip penetration and entrainment rate, which is related to the limited effect range of gas-jet. 


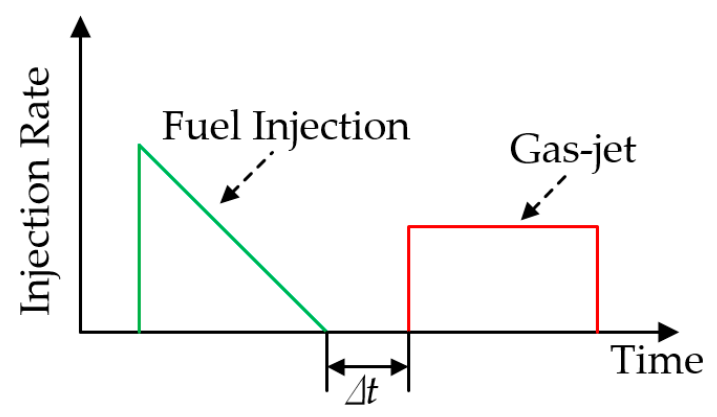

Figure 12. Schematic diagram of the ramping-down injection with gas-jet.

Table 5. Calculation conditions for gas-jet.

\begin{tabular}{cc}
\hline Items & Parameters \\
\hline Gas-jet composition by volume & O2: $0.5 \%, \mathrm{~N} 2: 87.4 \%, \mathrm{CO} 2: 4.8 \%, \mathrm{H} 2 \mathrm{O}: 7.3 \%$ \\
Injection pressure & $4.0 \mathrm{MPa}$ \\
Gas temperature & $1015 \mathrm{~K}$ \\
Gas density & $13.30 \mathrm{~kg} / \mathrm{m}^{3}$ \\
Injection interval & $0.05 \mathrm{~ms}$ \\
Injection duration & $0.2 \mathrm{~ms}$ \\
Injection velocity & $100 \mathrm{~m} / \mathrm{s}, 200 \mathrm{~m} / \mathrm{s}$ \\
\hline
\end{tabular}

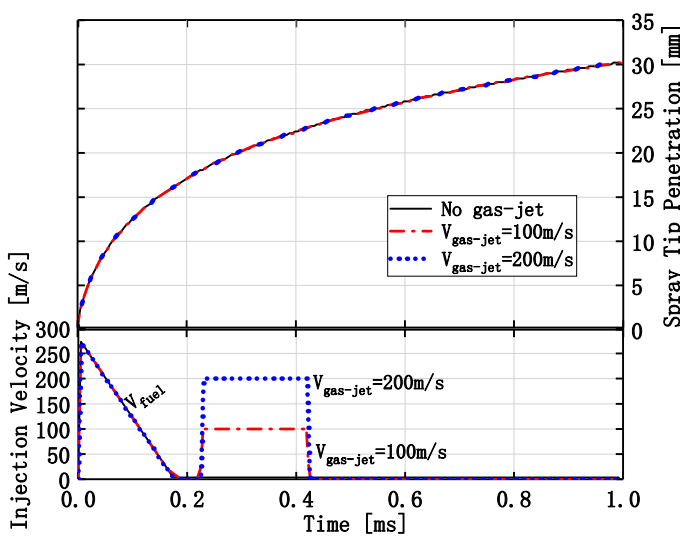

(a)

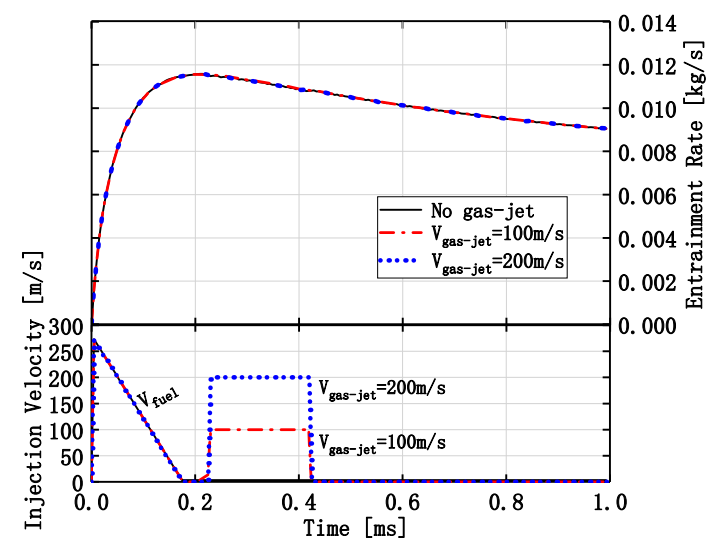

(b)

Figure 13. Spray tip penetrations (a) and entrainment rates (b) of the ramping-down injection with gas-jet and the ramping-down injection without gas-jet (black solid lines: ramping-down injection without gas-jet; red chain lines: ramping-down injection with gas-jet of $100 \mathrm{~m} / \mathrm{s}$; blue dotted lines: ramping-down injection with gas-jet of $200 \mathrm{~m} / \mathrm{s}$ ).

Figure 14 shows the variations of equivalence ratio of the ramping-down injection without gas-jet and the ramping-down injection with gas-jet. It is obvious that the gas-jet after EOI has a great impact on the equivalence ratio of spray tail mixture. On the one hand, the gas-jet makes the spray tail move downstream, and the higher the velocity of gas-jet, the farther the spray tail leaves from the nozzle exit and the larger the zone affected by the gas-jet. For instance, when it is at $t=0.48 \mathrm{~ms}$, the spray tail is around $4 \mathrm{~mm}$ away from the nozzle exit and the zone from the nozzle exit to $7.5 \mathrm{~mm}$ downstream is affected by the gas-jet with velocity of $100 \mathrm{~m} / \mathrm{s}$, while the spray tail is near $6 \mathrm{~mm}$ away from the nozzle exit and the zone from the nozzle exit to $10 \mathrm{~mm}$ downstream is affected in the case of gas-jet with velocity of $200 \mathrm{~m} / \mathrm{s}$. Under the action of the gas-jet, the stagnant fuel near the nozzle exit due to the influence of entrainment wave can flow downstream quickly, so the formation of fuel-lean zone near the nozzle exit is reduced and the following combustion environment is improved, decreasing the generation of soot and HC. Nevertheless, because of the rapid momentum exchange with low 
velocity mixture in spray tail, the gas-jet is not strong enough to affect the downstream zone any more. Thus, the ramping-down injection with gas-jet keeps the same equivalence ratio in the spray downstream as the ramping-down injection without gas-jet. In addition, owing to the limited effect range of gas-jet, there is almost no difference in spray tip penetration and overall entrainment rates between the ramping-down injection without gas-jet and the ramping-down injection with gas-jet as Figure 13 shows.



Figure 14. Equivalence ratio of the ramping-down injection with gas-jet and the ramping-down injection without gas-jet (solid lines: ramping-down injection without gas-jet; chain lines: ramping-down injection with gas-jet of $100 \mathrm{~m} / \mathrm{s}$; dotted lines: ramping-down injection with gas-jet of $200 \mathrm{~m} / \mathrm{s}$ ).

On the other hand, since the fuel in the spray tail flows downstream quickly due to the gas-jet, so more fuel accumulates in the new spray tail, which makes the equivalence ratio peak increase slightly. But the velocity of gas-jet has little impact on the equivalence ratio peak. Therefore, compared with the ramping-down injection without gas-jet, the one with gas-jet has more potential to achieve complete combustion and reduce the emission of soot and HC by organizing the ideal fuel-air distribution.

\section{Conclusions}

To find the optimized injection strategy for lower pollutant emissions, the mixing process of diesel spray under varying injection rate shapes has been studied in this paper by using a modified one-dimensional discrete spray model. The calculations were performed with five injection rate shapes: triangle, ramping-up, ramping-down, rectangle and trapezoid. Then the spray penetrations, entrainment rates and equivalence ratio distributed along the spray axial distance were analyzed. And this paper also discussed the ameliorative mixing characteristic of the multiple-injection strategy that was combined by the ramping-down and ramping-up injection rates, with the impact of the gas-jet after EOI on mixture distribution and pollutant emission reduction under the ramping-down injection rate shape investigated too. The conclusions are summarized as follows:

(1) The higher injection rate leads to the larger spray tip penetration during the initial injection and the higher maximum injection rate leads to the larger spray tip penetration finally.

(2) The ramping-up injection rate needs 1.5 times the injection duration for the entrainment wave to arrive at the spray tip. For the other four injection rates, the sprays can be treated as steady-like state, needing twice the injection duration from EOI to the time the entrainment wave reaches the spray tip. The concept using $U_{\mathrm{EOI}}$ to represent the average entrainment wave and spray penetration speed is easy and effective to estimate the time when the entrainment wave arrives at the spray tip. 
(3) The ramping-down injection rate enhances the spray penetration and mixing rate during the initial period, and obtains an almost even distribution of the equivalence ratio along the spray axis after EOI. The ramping-up injection rate leads to the leaner mixture after EOI and even much leaner near the nozzle exit, which are useful to control the combustion process with longer ignition delay and decrease the soot emissions.

(4) The spray characteristic summaries about the penetration and entrainment rate as well as equivalence ratio can provide a certain guidance and reference for practical application.

(5) The multiple-injection consisting of the ramping-down and ramping-up injection rates can obtain much higher entrainment rates than the ramping-down single injection, and the equivalence ratio of the former is much lower near the nozzle exit than that of the latter.

(6) The gas-jet after EOI has no obvious effect on the spray tip penetration and overall entrainment rate because the momentum of gas-jet is limited and the affected zone is small. However, the gas-jet after EOI has a great impact on the equivalence ratio of spray tail mixture. The spray tail will move downstream quickly under the action of the gas-jet. The higher the velocity of gas-jet, the farther the spray tail leaves from the nozzle exit and the larger the zone affected by the gas-jet. With the gas-jet after EOI, the equivalence ratio in spray tail will increase slightly due to the more fuel accumulated.

Author Contributions: Conceptualization, L.L.; methodology, I.N.; software, Q.M.; validation, I.N. and Q.M.; formal analysis, L.L. and X.M.; data curation, I.N.; writing-original draft preparation, Q.M.; writing-review and editing, L.L.; project administration, X.M.

Funding: This research was supported by National Natural Science Foundation of China (Grant No. 51509051), Natural Science Foundation of Heilongjiang Province of China (Grant No. LC2015017), and Marine Power Research and Development Program (grant number DE0302).

Conflicts of Interest: The authors declare no conflicts of interest.

\section{References}

1. Miyaki, M.; Takeuchi, K.; Kojima, A.; Uchiyama, K.; Nakagawam, M.; Herrmann, O.E.; Maassen, F.; Laumen, H.J. Fulfilling Euro 6 Emission Regulations for Heavy Duty Engines without SCR-System-A Challenge to the FIE System. Fortschritt-Berichte VDI Reihe 12. Verkehrstechnik-Fahrzeugtechnik 2011, 2, $196-211$. Available online: http://d.oldg.wanfangdata.com.cn/NSTLQK_NSTL_QKJJ0222007139.aspx (accessed on 17 October 2019).

2. Matsumoto, S.; Klose, C.; Schneider, J.; Nakane, N.; Ueda, D.; Kondo, S. 4th Generation Diesel Common Rail System: Realizing Ideal Structure Function for Diesel Engine. SAE Tech. Pap. 2013, 2. [CrossRef]

3. Wang, L.; Lowrie, J.; Ngaile, G.; Fang, T. High Injection Pressure Diesel Sprays from a Piezoelectric Fuel Injector. Appl. Therm. Eng. 2019, 152, 807-824. [CrossRef]

4. Boccardo, G.; Millo, F.; Piano, A.; Arnone, L.; Manelli, S.; Fagg, S.; Gatti, P.; Herrmann, O.E.; Queck, D.; Weber, J. Experimental investigation on a 3000 bar fuel injection system for a SCR-free non-road diesel engine. Fuel 2019, 243, 342-351. [CrossRef]

5. Peng, Z.; Liu, B.; Wang, W.; Lu, L. CFD Investigation into Diesel PCCI Combustion with Optimized Fuel Injection. Energies 2011, 4, 517-531. [CrossRef]

6. Kim, G.; Moon, S.; Lee, S.; Min, K. Numerical Analysis of the Combustion and Emission Characteristics of Diesel Engines with Multiple Injection Strategies Using a Modified 2-D Flamelet Model. Energies 2017, 10, 1292. [CrossRef]

7. Lee, C.; Chung, J.; Lee, K. Emission Characteristics for a Homogeneous Charged Compression Ignition Diesel Engine with Exhaust Gas Recirculation Using Split Injection Methodology. Energies 2017, 10, 2146. [CrossRef]

8. Liu, E.; Su, W. Study on Effects of Common Rail Injector Drive Circuitry with Different Freewheeling Circuits on Control Performance and Cycle-by-Cycle Variations. Energies 2019, 12, 564. [CrossRef]

9. Yang, S.; Moon, H.; Lee, C. A Study of Spill Control Characteristics of JP-8 and Conventional Diesel Fuel with a Common Rail Direct Injection System. Energies 2017, 10, 2104. [CrossRef]

10. Yang, S.; Lee, C. Experimental Research on the Injection Rate of DME and Diesel Fuel in Common Rail Injection System by Using Bosch and Zeuch Methods. Energies 2018, 11, 273. [CrossRef] 
11. Liu, L.; Peng, Y.; Ma, X.; Horibe, N.; Ishiyama, T. Phenomenological modeling of diesel spray with varying injection profile. J. Proc. Inst. Mech. Eng. Part D 2018, 233, 2780-2790. [CrossRef]

12. Bao, Z.; Horibe, N.; Ishiyama, T. A Study on Diesel Spray Characteristics for Small Quantity Injection. SAE Tech. Pap. 2018. [CrossRef]

13. Jafarmadar, S.; Shafee, S.; Barzegar, R. Numerical investigation of the effect of fuel injection mode on spray/wall interaction and emission formation in a direct injection diesel engine at full load state. Therm. Sci. 2010, 14, 1039-1049. [CrossRef]

14. Macian, V.; Payri, R.; Ruiz, S.; Bardi, M.; Plazas, A.H. Experimental Study of the Relationship between Injection Rate Shape and Diesel Ignition Using a Novel Piezo-actuated Direct-acting Injector. Appl. Energy 2014, 118, 100-113. [CrossRef]

15. Plamondon, E.; Seers, P. Development of a Simplified Dynamic Model for a Piezoelectric Injector Using Multiple Injection Strategies with Biodiesel/Diesel Fuel Blends. Appl. Energy 2014, 131, 411-424. [CrossRef]

16. Mohan, B.; Yang, W.; Yu, W.; Tay, K.L.; Chou, S.K. Numerical investigation on the effects of injection rate shaping on combustion and emission characteristics of biodiesel fueled CI engine. Appl. Energy 2015, 160, 737-745. [CrossRef]

17. Tay, K.L.; Yang, W.; Zhao, F.; Yu, W.; Mohan, B. Effects of triangular and ramp injection rate-shapes on the performance and emissions of a kerosene-diesel fueled direct injection compression ignition engine: A numerical study. Appl. Therm. Eng. 2017, 110, 1401-1410. [CrossRef]

18. Lamas, M.I.; Rodriguez, C.G. NOx Reduction in Diesel-Hydrogen Engines Using Different Strategies of Ammonia Injection. Energies 2019, 12, 1255. [CrossRef]

19. Han, C.; Yuan, C.; He, Y.; Liu, Y. Effect of Fuel Injection Rate Shapes on Mixture Formation and Combustion Characteristic in a Free-piston Diesel Engine Generator. Adv. Mech. Eng. 2018, 10. [CrossRef]

20. Mrzljak, V.; Medica, V.; Bukovac, O. Volume agglomeration process in quasi-dimensional direct injection diesel engine numerical model. Energy 2016, 115, 658-667. [CrossRef]

21. Cheng, Q.; Tuomo, H.; Kaarioa, O.T.; Marttia, L. Spray dynamics of HVO and EN590 diesel fuels. Fuel 2019, 245, 198-211. [CrossRef]

22. Marčič, S.; Marčič, M.; Wensing, M.; Vogel, T.; Praunseis, Z. A simplified model for a diesel spray. Fuel 2018, 222, 485-495. [CrossRef]

23. Musculus, M.P.B.; Kattke, K. Entrainment Waves in Diesel Jets. SAE Int. J. Engines 2009, 2, 1170-1193. [CrossRef]

24. Musculus, M.P.B. Entrainment Waves in Decelerating Transient Turbulent Jets. J. Fluid Mech. 2009, 638, 117-140. [CrossRef] 